\title{
Network Monitoring Tools and Techniques uses in the Network Traffic Management System
}

\author{
Wahyudin Rahman, Phong Thanh Nguyen, Muhamad Rusliyadi, E. Laxmi Lydia, K. Shankar
}

\begin{abstract}
Network Monitoring Tools, Vendors and software's domain is huge, without a doubt. For server IT monitoring and in an ever changing marketplace new utilities, tools and software are being invented pretty much consistently. We have experienced the same number of devices as we could discover and gathered together the best ones in simple to peruse position and featured their fundamental qualities and why it think they are in the top class of instruments to use in IT framework and business.
\end{abstract}

Keywords: Network Monitoring, tools, software, business, IT framework.

\section{INTRODUCTION}

For failing components or slow network monitoring is the utilization of a framework that continually screens a computer network. In case of outages or other problem it notifies the network administrator through SMS, email or other alerts. Monitoring of Network is the part of network management.

When problem is arrived than fix that network problem is not enough. Before occurring the problem the IT managers head off potential issues and proactively watch systems. This work measure performance, utilization and availability and also observes the traffic of network. Following features should offers by useful monitoring tools:

1. For sending alerts use a machine

2. In real time to detect outages have the ability

3. Integrations For network hardware integration, like NetFlow monitoring and SNMP

4. Network monitoring in real time

\section{Top Network Monitoring Tools and Techniques}

Some network monitoring tools and techniques are described as follows:

\section{Solarwinds Network Performance Monitor}

SolarWinds Network Performance Monitor is anything but difficult to arrangement and can be prepared in the blink of an

Revised Version Manuscript Received on 16 September, 2019.

* Correspondence Author

Wahyudin Rahman, Universitas Muhammadiyah Luwuk Banggai, Indonesia. E-mail: wahyu@unismuhluwuk.ac.id

Phong Thanh Nguyen*, Department of Project Management, Ho Chi Minh City Open University, Vietnam. E-mail: phong.nt@ou.edu.vn

Muhamad Rusliyadi, Polytechnic of Agricultural Development Yogyakarta-Magelang, Agricultural Extension and Human Resource Development Agency, Ministry of Agriculture, Indonesia.

E. Laxmi Lydia, Professor, Vignan's Institute of Information Technology(A), Department of Computer Science and Engineering, Visakhapatnam, Andhra Pradesh, India. E-mail: elaxmi2002@yahoo.com

K. Shankar, Department of Computer Applications, Alagappa University, India. E-mail: shankarcrypto@gmail.com eye. The apparatus consequently finds organize gadgets and conveys inside 60 minutes. Its basic way to deal with regulate a whole system makes it one of the least demanding to utilize and most natural UIs. 


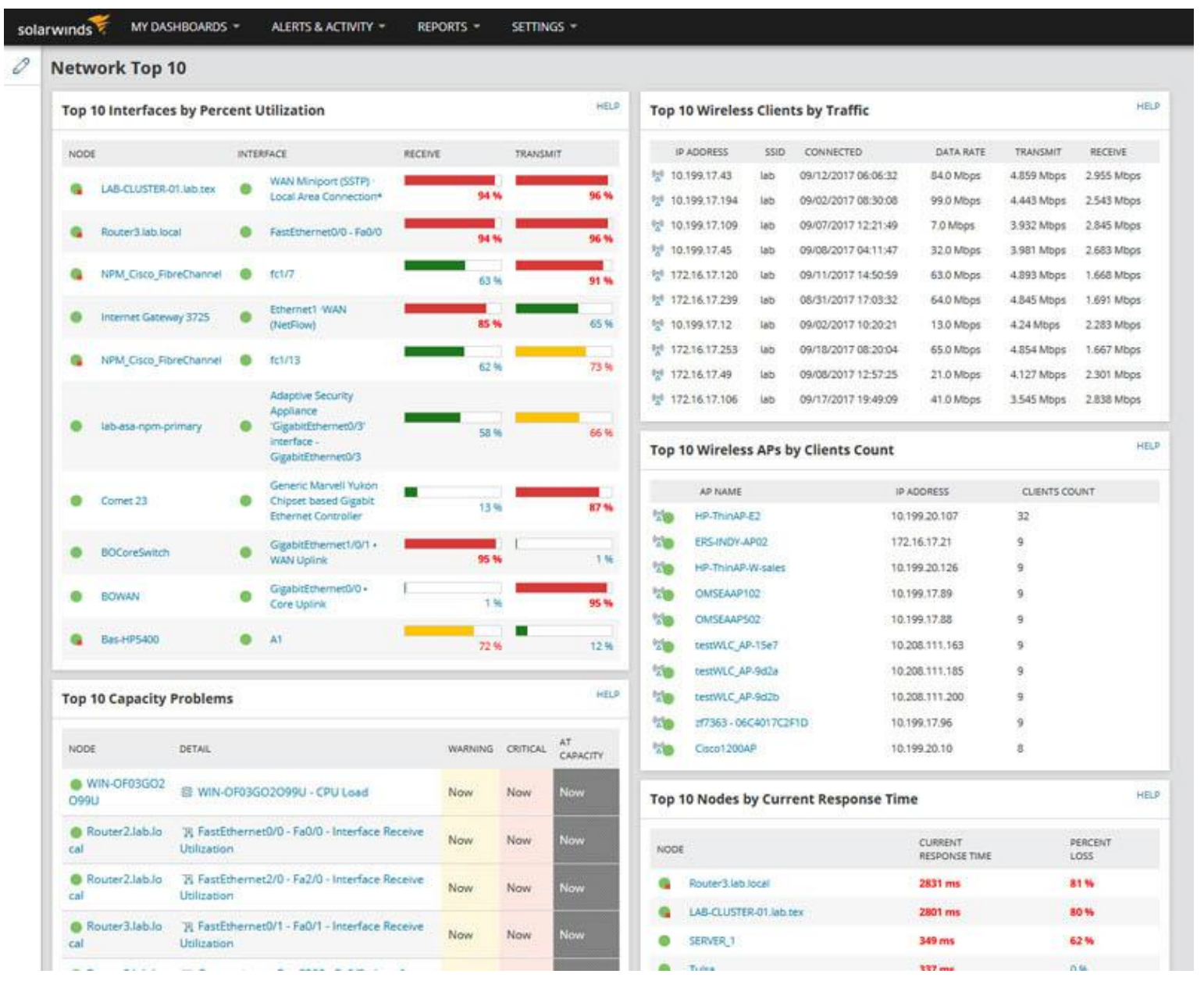

Figure 1: Solarwinds Network Performance Monitor

\section{PRTG Network Monitor from Paessler}

PRTG Network Monitor programming is usually known for its propelled framework the executives capacities. All gadgets, frameworks, traffic, and applications in system can be effectively shown in a various leveled see that outlines execution and alarms. PRTG screens IT framework utilizing innovation, for example, SNMP, WMI, SSH, Flows/Packet Sniffing, HTTP demands, REST APIs, Pings, SQL and significantly more.

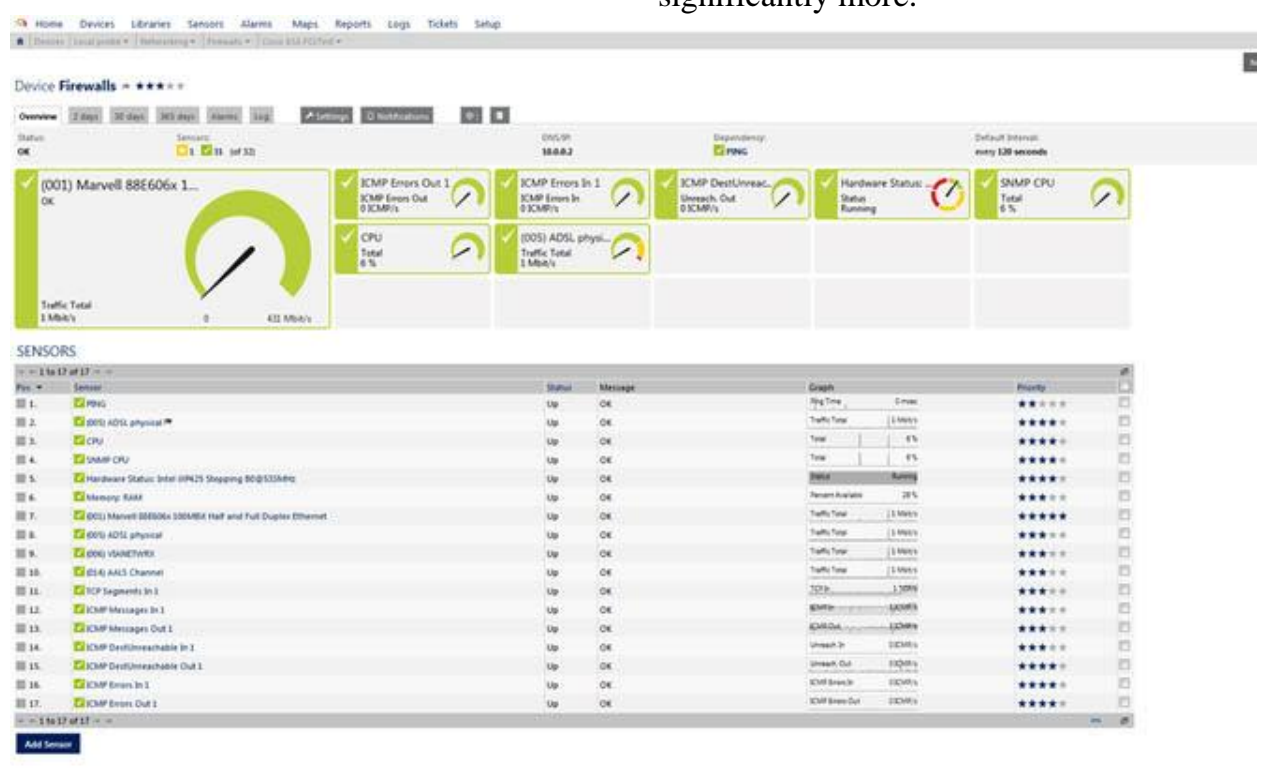

Figure 2: PRTG Network Monitor from Paessler 


\section{ManageEngine OpManager}

At its center, ManageEngine OpManager is a foundation the executives, organize checking and Application Performance Management "APM" (with APM module) programming.

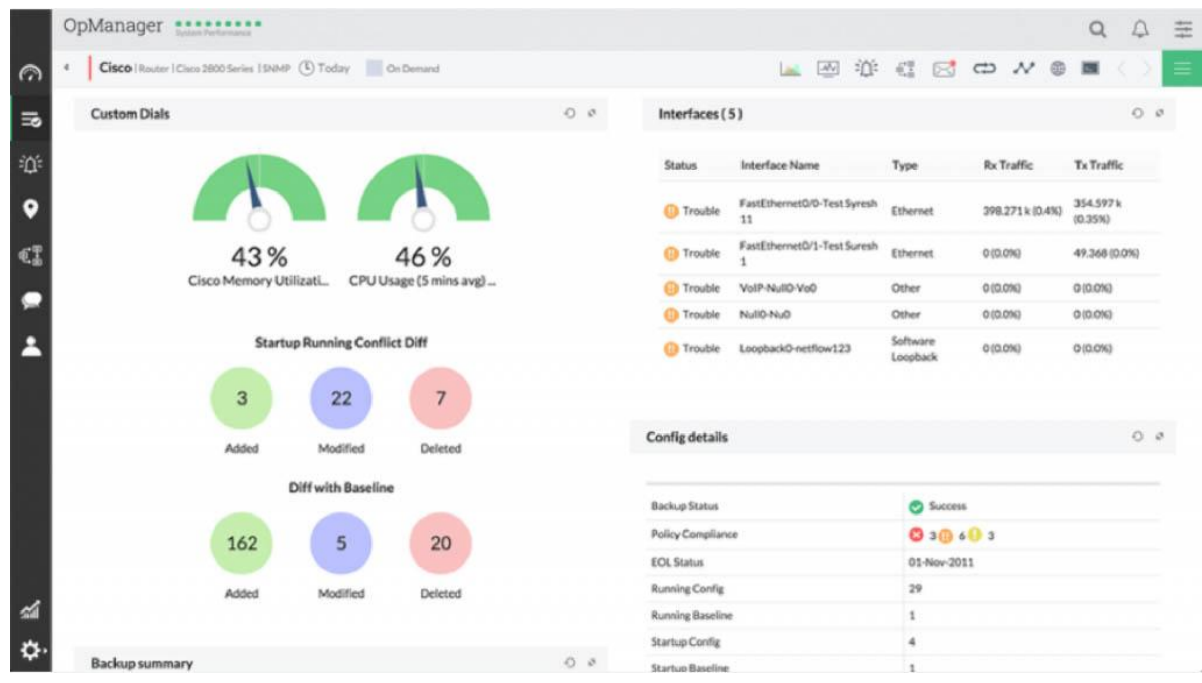

4. WhatsUp Gold 2017

WhatsUp Gold (WUG) is a system observing programming from Ipswitch. It is one of the most effortless to utilize and

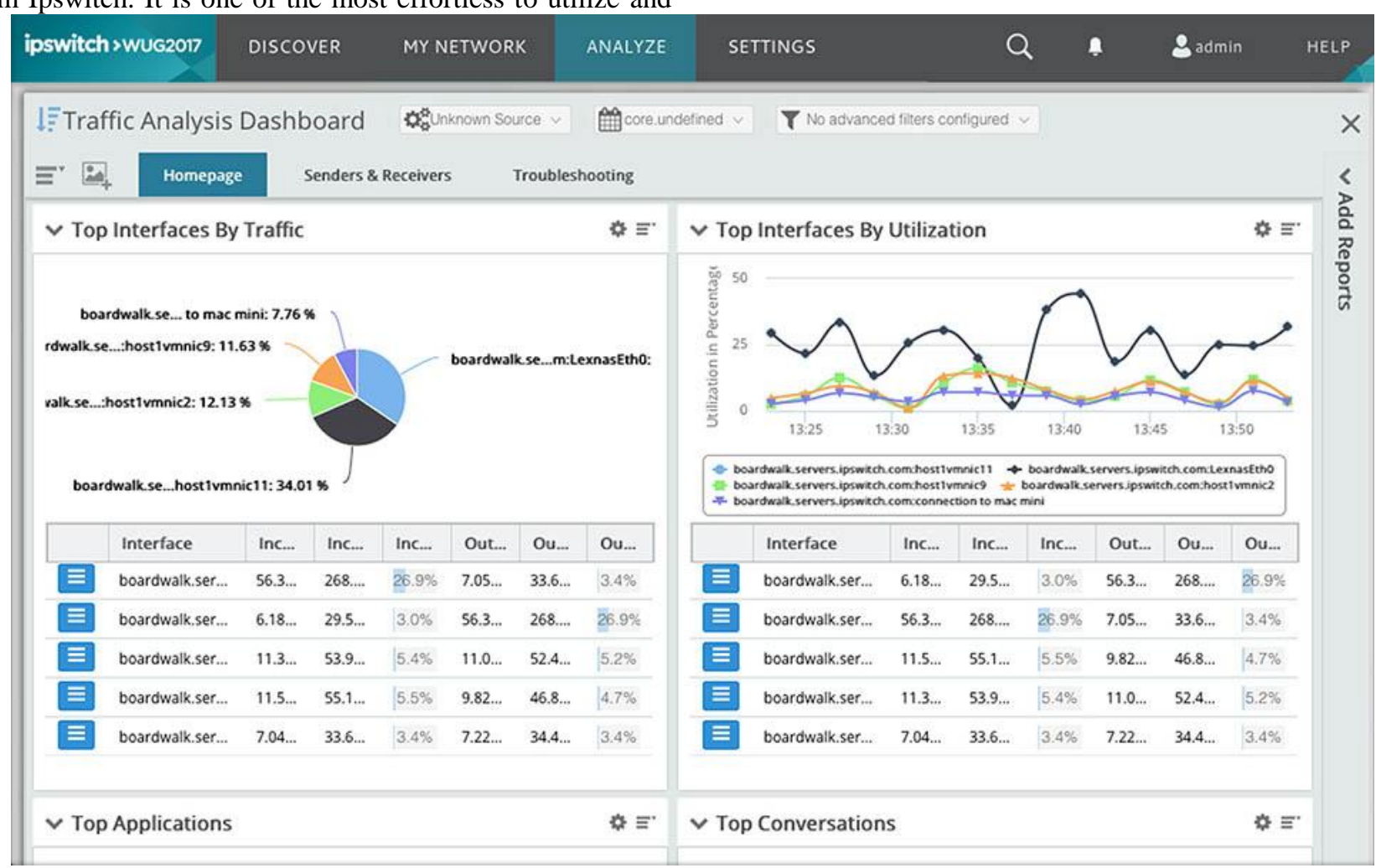

Figure 4: WhatsUp Gold 2017

\section{Nagios XI}

Nagios XI is gone for a wide group of spectators, from consultants, SMBs (Small-to-Medium-Business), to huge enterprises. This makes Nagios' XI estimating model one of the most adaptable. They have a free form, open-source, once profoundly configurable instruments in the market. The dashboards are easy to use and outwardly appealing. 


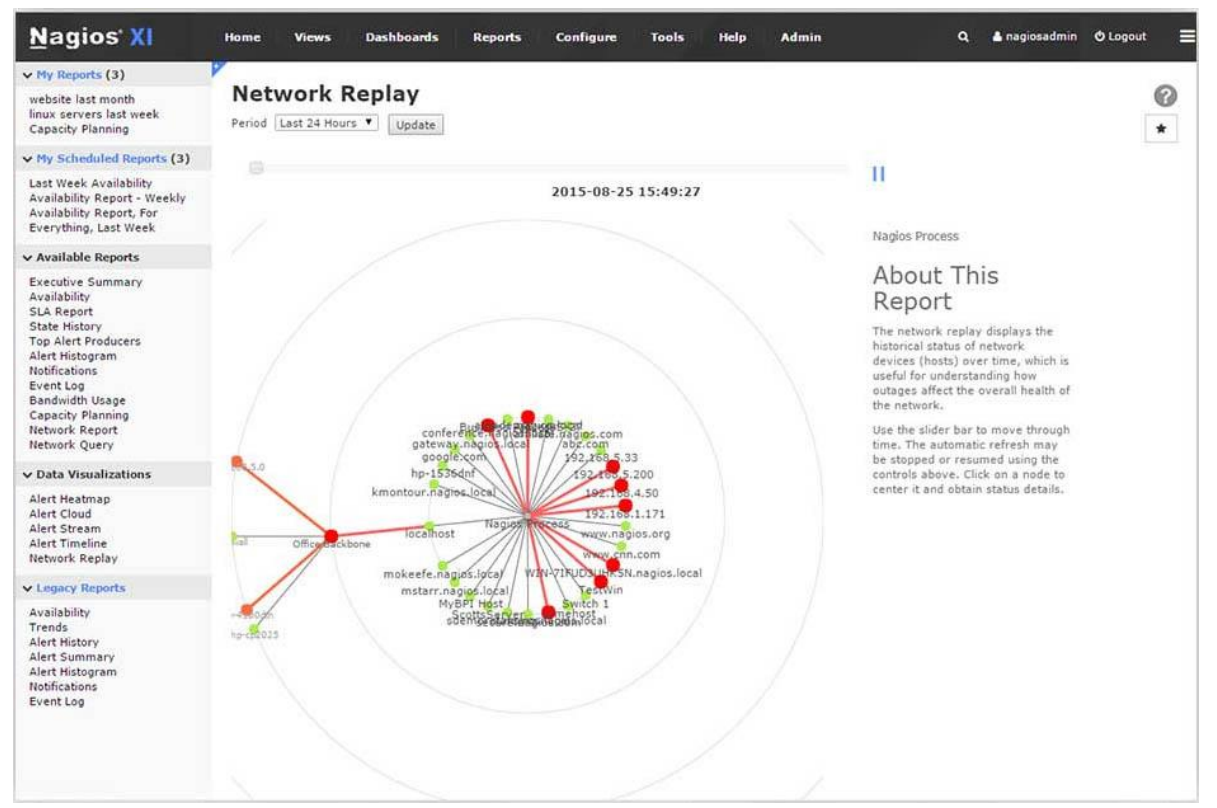

Figure 5: Nagios XI

\section{Zabbix}

Zabbix is an open source checking device. It is famous for its simple to-utilize and satisfying Web GUI that is completely configurable. Zabbix centers around checking and inclining usefulness. This product is habitually utilized for checking servers and system equipment. One of the features of Zabbix is that it can foresee inclines in rush hour gridlock. Zabbix can conjecture future conduct dependent on recorded information.

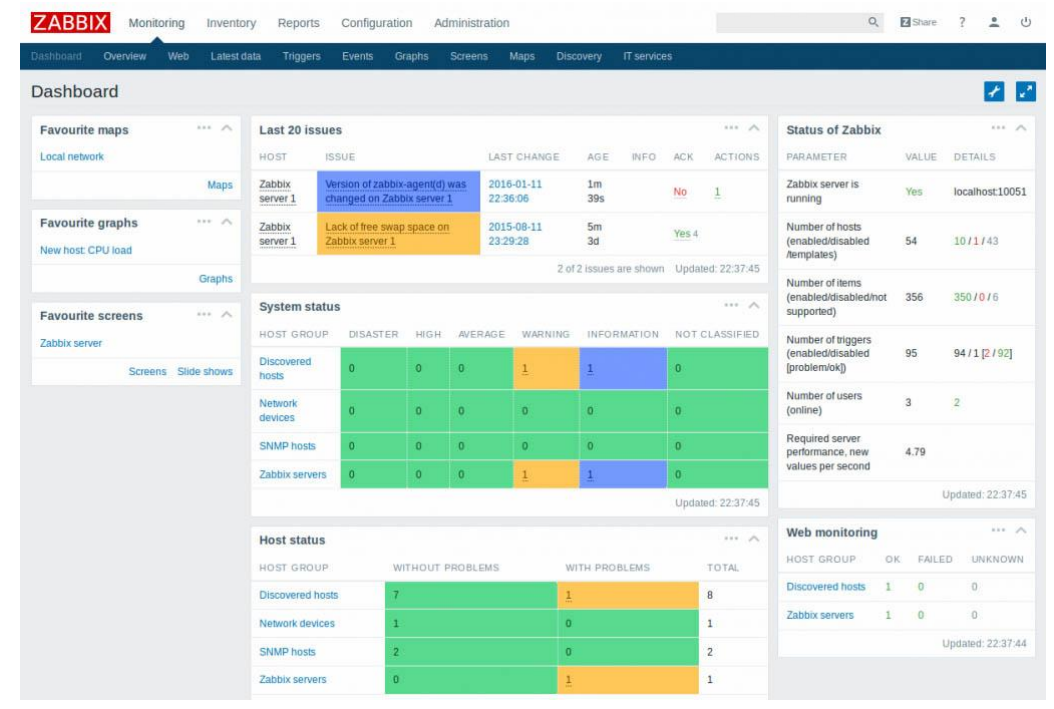

Figure 6: Zabbix

\section{Incinga}

It is another open source framework and administration checking apparatus. Icinga was created in 2009 by a similar group of engineers that brought you Nagios. It is a simple to utilize and adaptable apparatus for SMB and undertaking systems. The product centers firmly around observing foundation and administrations. The device likewise incorporates incredible edge investigation and report/ready functionalities. 


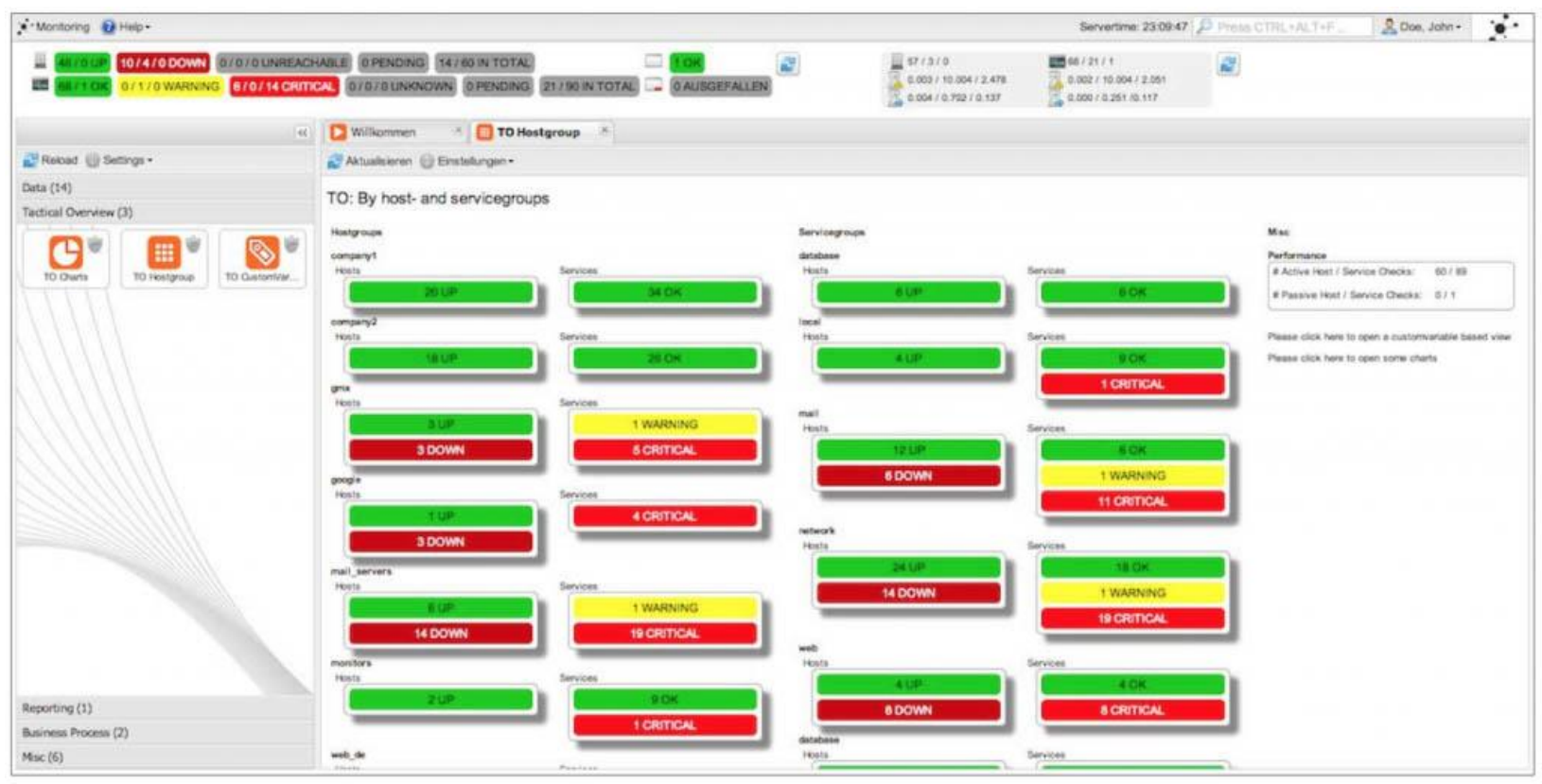

\section{Datadog}

It is a checking administration uncommonly intended for crossover cloud situations. Datadog can likewise screen the
Figure 7: Incinga

presentation of system, applications, apparatuses, and administrations. One of the features of Datadog is that it can give extensibility however numerous APIs (Application Programming Interfaces) with awesome documentation.

\section{\$DATADOG}
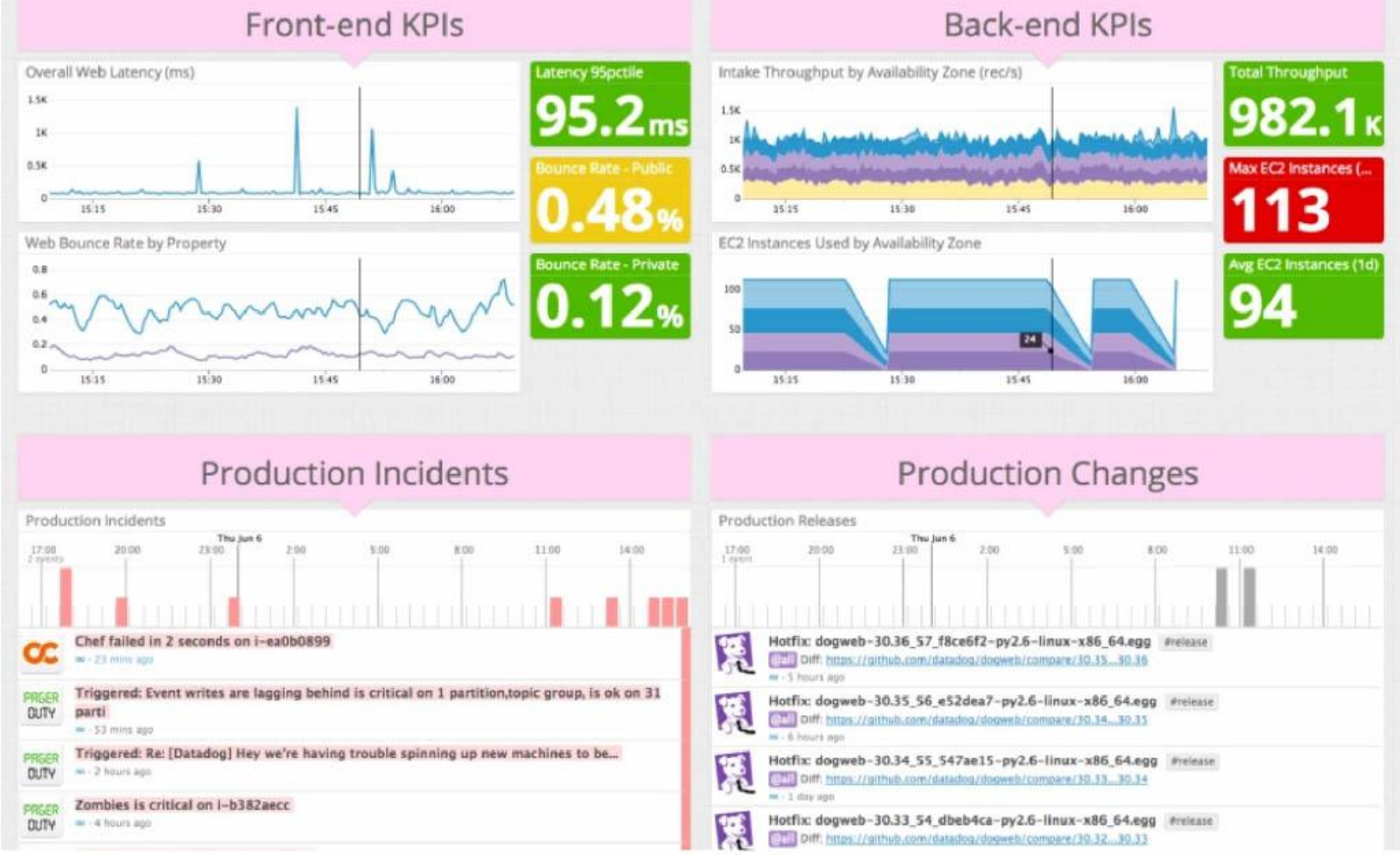

Figure 8: Datadog

\section{ConnectWise Automate}

Once in the past known as Labtech, ConnectWise Automate is another cloud-based director and observing arrangement that can monitor your IT framework gadgets from a solitary area.
ConnectWise Automate finds all gadgets in your system so they can be checked proactively. The system perceivability is improved on the grounds that the device 
deciphers issues and starts a programmed pre-characterized activity to moderate the issue.

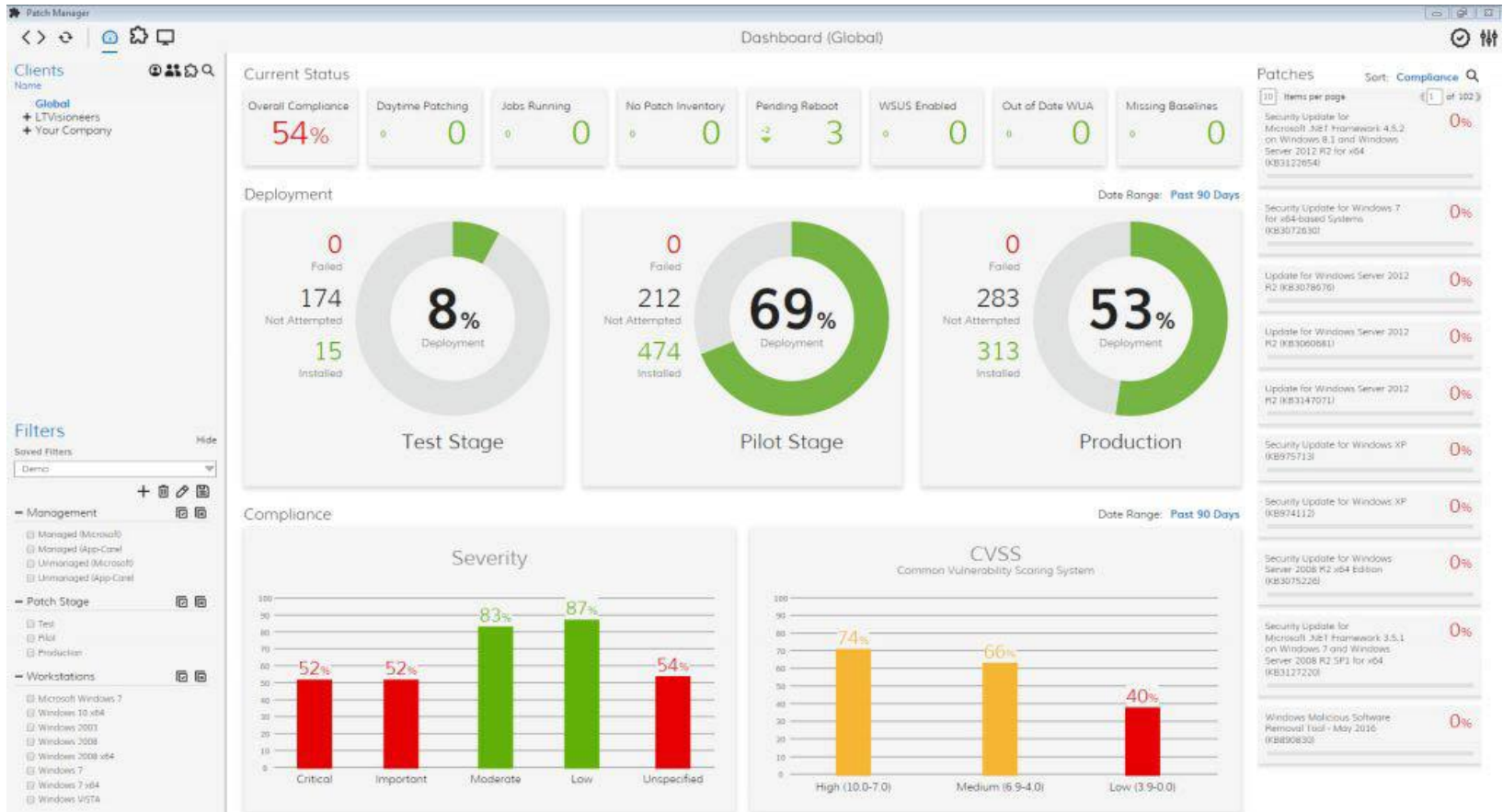

Figure 9: ConnectWise Automate

LogicMonitor can help distinguish approaching issues by giving prescient adjusts and pattern examination.

\section{Logic Monitor}

LogicMonitor is a mechanized SaaS (Software-as-a-Service) IT execution observing apparatus. With LogicMonitor you can get full perceivability of the presentation and soundness of your system. This product will consequently find IT framework gadgets and screen them proactively. Other than from remarkable checking capabilites, the product likewise improves the presentation and wellbeing of your system.
Rationale Monitor is prominent on the grounds that it accompanies an exceptionally adaptable dashboard, alarms, and reports. The product underpins more than 1000 distinct advancements, including half breed cloud and systems administration gadgets, so as to give granular execution measurements.

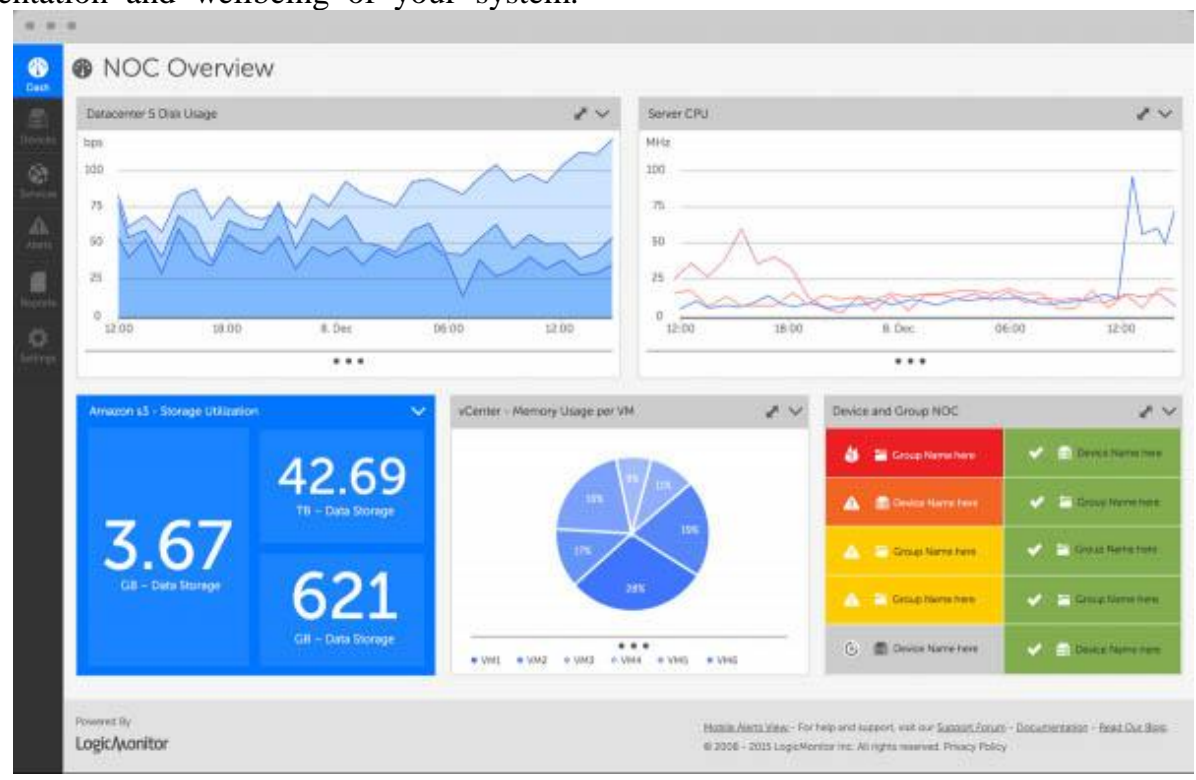

Figure 10: Logic Monitor

\section{TYPES OF NETWORK TRAFFIC}

By an increasing critical set of data traffic the network can accommodate. To facilitate the optimization of network identify the traffic type will help administrators of networks. 


\begin{tabular}{|l|l|l|l|}
\hline Traffic Type & Example & Problem & Solution \\
\hline Bursty Traffic & $\begin{array}{l}\text { Downloads of FTP, } \\
\text { graphic, video content }\end{array}$ & $\begin{array}{l}\text { Consumes high } \\
\text { bandwidth and } \\
\text { Starves applications }\end{array}$ & $\begin{array}{l}\text { Set constraint to limit } \\
\text { access to bandwidth }\end{array}$ \\
\hline Interactive Traffic & $\begin{array}{l}\text { SSL trans actions, M, } \\
\text { Telnet sessions }\end{array}$ & $\begin{array}{l}\text { Susceptible to } \\
\text { competition for } \\
\text { bandwidth and results } \\
\text { in poor response time }\end{array}$ & $\begin{array}{l}\text { Prioritize over less } \\
\text { essential trafic }\end{array}$ \\
\hline $\begin{array}{l}\text { Latency Sensitive } \\
\text { Traffic }\end{array}$ & $\begin{array}{l}\text { Streaming } \\
\text { applications, Voice } \\
\text { over IP, video } \\
\text { conferencing }\end{array}$ & $\begin{array}{l}\text { Susceptible to } \\
\text { competition for } \\
\text { bandwidth and results } \\
\text { in poor response time }\end{array}$ & $\begin{array}{l}\text { Set minimum and } \\
\text { maximum bandwidth } \\
\text { range based on } \\
\text { priority }\end{array}$ \\
\hline Non-Real Time Traffic & $\begin{array}{l}\text { Email, batch } \\
\text { processing } \\
\text { applications }\end{array}$ & $\begin{array}{l}\text { Consumes bandwidth } \\
\text { during business hours }\end{array}$ & $\begin{array}{l}\text { Schedule bandwidth } \\
\text { during non-business } \\
\text { hours }\end{array}$ \\
\hline
\end{tabular}

Table: Types of Network Traffic

\section{MANAGEMENT OF BANDWIDTH}

For avoiding the overfilling the link the process that control and measure the traffic on network is known as bandwidth management. For working smooth and fast connection of internet it helps the network. Identify the reason of heavy traffic, traffic is analyzed and measured for management of bandwidth. For scheduling the usages of bandwidth and avoiding the unwanted traffic it uses the network traffic control tool. The factors that decrease the link performance are:

1. For the notification of explicit congestion no proper support

2. Due to queueing in routers it created higher latency

3. Until packets are dropped by TCP using flooding it determined the capacity.

4. In waste of bandwidth TCP global synchronization with the network reaching its capacity

5. By Internet Service Providers Queue management is controlled

\section{Spare bandwidth needed by Bursty traffic}

Measuring of Traffic - Packet sniffers take a gander at individual parcels and help to follow dubious issues. Be that as it may, they are voluminous and require the learning of system conventions. So traffic estimating devices are utilized to get more extensive perspective on the sum and kind of traffic on a specific system. A portion of the apparatuses include:

1. For monitoring bandwidth usages of bandwidth PRTG

2. For detecting network anomalies and monitoring of NetFlow use Caligare Flow

3. For managing and measuring network traffic use of Sandvine Intelligent Network Solutions

4. For and traffic shaping and bandwidth management use of FireBeast

5. For analyzing and monitoring use Exbander Precision

Shaping of Traffic. It controls the volume of traffic sent in a particular period. Ordinarily, it is applied at the edges of the system to control the section of traffic, however now and again, it is applied at the source or by a component in the network.

Limiting the Rate - A technique to control the traffic rate sent or got on a system interface is alluded to as rate limiting. At the point when traffic is not exactly or equivalent to the predefined rate, it is sent and when it surpasses the predetermined rate, it is dropped or deferred. It is performed in the accompanying ways.

Congestion control - It control the congestion mechanism of protocol.

Queuing - It can apply to any protocol of network like IPv6 and in transit it delays packets.

Policing - It can apply to any protocol of network like IPv6 and excess packets discards by this.

\section{CONCLUSION}

By improving security, performance and efficiency into a managed resource besides transforming the network the process of controlling and monitoring the activities of network is known and Network traffic management. To maintain, operate and administer the network system it helps.

\section{REFERENCES}

1. Cabezas, C.A.; Medina, G.R.; Pea, T.M.N.; Labrador, A.M. Low energy and low latency in wireless sensor networks. In Proceedings of the IEEE International Conference on Communications (ICC-09), Dresden, Germany, 14-18 June 2009; pp. 1-5.

2. Chienwattanasook, K., Wattanapongphasuk, W., Prianto, A., \& Jermsittiparsert, K. 2019. "Corporate Entrepreneurship and Business Performance of Logistic Companies in Indonesia." Industrial Engineering \& Management Systems 18 (3): 538-547.

3. Dawabsheh, M., Hussein, A., \& Jermsittiparsert, K. 2019. "The Triangular Relationship between TQM, Organizational Excellence and Organizational Performance: A Case of Arab American University Palestine.” Management Science Letters 9 (6): 921-932.

4. Jermsittiparsert, K., Siam, M., Issa, M., Ahmed, U., \& Pahi, M. 2019. "Do Consumers Expect Companies to Be Socially Responsible? The Impact of Corporate Social Responsibility on Buying Behavior.' Uncertain Supply Chain Management 7 (4): 741-752.

5. Syazali, M., Putra, F., Rinaldi, A., Utami, L., Widayanti, Umam, R., \& Jermsittiparsert, K. 2019. "Partial Correlation Analysis Using Multiple Linear Regression: Impact on Business Environment of Digital Marketing Interest in the Era of Industrial Revolution 4.0.' Management Science Letters 9 (11): 1875-1886.

6. Sae-Lim, P. \& Jermsittiparsert, K. 2019. "Is the Fourth Industrial Revolution a Panacea? Risks toward the Fourth Industrial Revolution: Evidence in the Thai Economy." International Journal of Innovation, Creativity and Change 5 (2): 732-752.

7. Chatchawanchanchanakij, P., Arpornpisal, C., \& Jermsittiparsert, K. 2019. "The Role of Corporate Governance in Creating a Capable Supply Chain: A Case of Indonesian Tin Industry." International Journal of Supply Chain Management 8 (3): 854-864.

8. Hartinah, S., Suharso, P., Umam, R., Syazali, M., Lestari, B., Roslina, R., \& Jermsittiparsert, K. 2020. "Teacher's Performance Management: The Role of Principal's Leadership, Work Environment and Motivation in Tegal City, Indonesia." Management Science Letters 10 (1): 235-246.

9. Haseeb, M., Hussain, H., Slusarczyk, B., \& Jermsittiparsert, K. 2019. "Industry 4.0: A Solution towards Technology Challenges of Sustainable Business Performance.” Social Sciences 8 (5): 184. 